DOI 10.37882/2223-2982.2020.09.35

\title{
ЛЕКСИЧЕСКИЕ И МОРФОСИНТАКСИЧЕСКИЕ СРЕДСТВА ВЫРАЖЕНИЯ СЕМАНТИЧЕСКОГО СУБЪЕКТА В ОБОБЩАЮЩИХ ВЫСКАЗЫВАНИЯХ НЕМЕЦКОГО И РУССКОГО ЯЗЫІКОВ
}

\section{LEXICAL AND MORPHO SYNTACTICAL MEANS OF EXPRESSING SEMANTIC SUBJECT IN GENERALIZING STATEMENTS IN GERMAN AND RUSSIAN \\ A. Chervoniy E. Murashova}

Summary: The paper is dedicated to the study of lexical and morpho syntactical means of expressing semantic subject in generalizing statements in German and Russian.

As a result of complex comparative analysis done on the verge of anthropocentric and structural-systematic paradigms the author systemized lexical and morpho syntactical means of expressing semantic subject. The paper studies similarities and differences in systematic morpho syntactical means of expressing semantic subject in German and Russian. The analysis of generalizing statements proved some syncretism: morphological and syntactical means when crisscrossing with lexis serve as a formal means of deleting semantic subject.

Keywords: semantic subject, generalizing statements, formal deleting, the German language, the Russian language.
И сследование выполнено при финансовой поддержке Российского фонда фундаментальных исследований (РФФИ) в рамках научного проекта № 19-012-00062 «Полифония семантического субъекта (на материале русского, французского, английского и немецкого языков», проводимого в ФГБОУ ВО «РГЭУ (РИНХ)»; руководитель - доктор филол. наук, доцент, заведующий кафедрой немецкого и французского языков А.М. Червоный.

В условиях современной всеохватывающей глобализации всё более актуальными становятся сопоставительные исследования морфосинтаксических категорий, претендующих на статус универсальных, полноценно идентичных в различных языках. Поиск и интерпретация совпадений и различий между национальными языковыми системами на лексико-грамматическом уровне позволяют приблизиться к расшифровке уникальных кодов оязыковления внелингвистической реальности, в том числе в отношении особенностей представления семантического субъекта.

\author{
Червоный Александр Михайлович \\ Д.филол.н., дочент, Таганрогский институт \\ имени А.П. Чехова (филиал) ФГБОУ ВПО «РГЭУ (РИНХ)» \\ ckutrik@yandex.ru \\ Мурашова Евгения Анатольевна \\ К.филол.н., дочент, Таганрогский институт \\ имени А.П. Чехова (филиал) ФГБОУ ВПО «РГЭУ (РИНХ)» \\ shenetschka@rambler.ru
}

Аннотация: В статье рассматриваются лексические и морфосинтаксические способы выражения семантического субъекта в обобщающих высказываниях немецкого и русского языков.

В результате комплексного сопоставительного исследования, осуществленного на стыке антропоцентрической и системно-структурной парадигм, были систематизированы морфосинтаксические и лексические способы выражения семантического субъекта. В работе рассматривается сходство и отличие морфосинтаксических систем выражения семантического субъекта в немецком и русском языках. Анализ обобщающих высказываний подтвердил свойственный им синкретизм: морфологические и синтаксические средства регулярно пересекаясь с лексическими средствами, служат формальным средством устранения семантического субъекта.

Ключевые слова: семантический субъект, обобщающее высказывание, формальное устранение, русский язык, немецкий язык.

Данная статья посвящена сопоставительному анализу морфосинтаксических способов выражения семантического субъекта в обобщающих высказываниях русского языка в сравнении с их немецкими эквивалентами. К задачам исследования относится также уточнение оснований для выделения отдельных групп морфосинтаксических способов выражения семантического субъекта в обобщающих высказываниях русского и немецкого языков с учётом особенностей их лексического состава и грамматического строя.

Рассматривая морфосинтаксические способы выражения семантического субъекта в обобщающих высказываниях, мы ориентировались на алгоритмы комплексного сопоставительного исследования, учитывающего положения антропоцентрической и системно-структурной парадигм, а также алгоритмы дистрибутивного анализа.

Данный подход позволил осуществить сопоставительный анализ морфосинтаксических средств выраже- 
ния субъекта, представленных в идентичном контекстуальном окружении.

Морфосинтаксические средства выражения субъекта описываются с учётом их дистрибутивного вектора, детерминируемого условиями коммуникативной ситуации и конвенционально закреплёнными нормами систем немецкого и русского языков.

Компаративный анализ лексических и морфосинтаксических средств выражения субъекта проводился на материале художественного дискурса, в частности на материале оригинального и переводного текстов М. Булгакова «Мастер и Маргарита».

Реализация универсальной категории обобщённости сопровождается формальным устранением семантического субъекта, под которым понимается активное, разумное, обладающее речемыслительной деятельностью существо - человек.

В немецком языке в качестве специальных морфосинтаксических средств формального устранения субъекта используются: неопределённо-личное местоимение man в сочетании с глаголом третьего лица единственного числа в форме активного и пассивного залогов настоящего времени (в особенности модальные глаголы в форме активного залога настоящего времени); множественное число нарицательных существительных, представляющих ряд схожих субъектов; неопределённый или нулевой артикль; мужской, женский и средний род в обобщающем значении. Рассмотрим их подробнее, сопоставляя со средствами формального выражения субъекта в русском языке.

Для обозначения действий субъектов в обобщающих высказываниях во многих языках, в том числе и в немецком, часто используется настоящее время глаголов. Такие действия, как правило, безотносительны ко времени или являются регулярно повторяющимися. Особенно часто в обобщающих высказываниях немецкого языка в настоящем времени реализуются модальные глаголы, и в первую очередь глагол können в сочетании с неопределённо-личным местоимением man:

Например:

1. «Tiger kann man nicht essen», - sagte Gella [6, c. 389].

2. Und ein Faktum ist das Hartnäckigste, was man sich denken kann [6, c. 383].

В русском языке таким высказываниям соответствуют безличные предложения с модальными предикатами: Например:

1. «Тигров нельзя есть», - сказала Гелла [7, с. 257] или обобщающие высказывания с нулевой связкой

2. А факт - самая упрямая в мире вещь [7, с. 253].
Это же касается и немецких пассивных конструкций с обобщающим значением, где настоящее время может выражать безотносительное ко времени действие:

- «lch kann nicht schießen, wenn neben mir geredet wird!», - schrie Behemoth... [6, с. 393].

В русском языке таким конструкциям соответствуют неопределённо-личные предложения с глаголами в третьем лице мн. числа:

- «Я не могу стрелять, когда под руку говорят!», кричал Бегемот... [7, с. 260].

В данной позиции действие, выражаемое смысловым глаголом, может быть отнесено к любому потенциальному деятелю, не названному конкретно, но представляющему собой лицо, информация о котором выводима из контекста.

Если в пассивных конструкциях немецкого языка инициатор действия остаётся неназванным (двучленный пассив), в качестве такового может подразумеваться фактически любой семантический субъект [1, с. 265-313]. Соответственно, высказывания такого типа отличаются наибольшей степенью обобщённости. Например: Вам отрежут голову! [2, с. 12]. - Ihnen wird der Kopf vom Rumpf getrennt! [6, с. 19].

Немецкому пассивному залогу соответствует неопределённо-личные предложения с глаголами в третьем лице мн. числа в форме изъявительного или повелительного наклонения.

Универсальным, реализуемым как в немецком, так и в русском языках, лексическим средством выражения семантического субъекта в обобщающих высказываниях являются нарицательные существительные во множественном числе, например, Menschen, Leute, представляющих ряд субъектов, объединённых общим признаком или функцией:

Например:

1. «Hört auf!», - rief Voland, - «Was sind doch die heutigen Menschen nervös» [6, c. 364].

2. "Да перестаньте», - крикнул Воланд, - «до чего нервозны современные люди» [7, с. 241].

Данные лексико-грамматические средства репрезентируют дополнительное значение количественной неопределённости обозначаемых субъектов.

О качественной неопределённости в немецком языке, с нашей точки зрения имеет смысл говорить, также в случае актуализации в обобщающем высказывании неопределённого или нулевого артикля.

Наличие в немецком языке перед существительным, обозначающим деятеля, неопределённого артикля традиционно рассматривается в качестве одного из генера- 
лизирующих морфосинтаксических алгоритмов [2, с. 5].

Например: Einen Schriftsteller erkennt man nicht am Ausweis, sondern an dem, was er schreibt [6, c. 496].

В русском языке такое средство отсутствует. Вместо него используются безличные предложения с безличным или личным глаголом в форме третьего лица ед. числа, соотносимым с существительным или местоимением среднего рода: ...вовсе не удостоверением определяется писатель, а тем, что он пишет! [7, с. 328].

Нулевая позиция артикля также может иметь генерализирующее значение во множественном числе [3, с. 34]: Например:

1. Теперь я вас понимаю: его выманили не люди, а его собственная мысль [7, с. 300].

2. Nicht Menschen haben ihn hinausgelockt, sondern seine eigenen Ziele [6, c. 453].

3. Котам обычно почему-то говорят «ты», хотя ни один кот никогда ни с кем не пил брудершафта [7, c. 268].

4. Kater werden aus irgendwelchen Gründen gewöhnlich mit du angeredet, obwohl noch niemals ein Kater mit irgendwem Brüderschaft getrunken hat [6, c. 405].

Несмотря на общие тенденции выражения семантического субъекта в обобщающих высказываниях рассматриваемых языков, нельзя не отметить наличие определенных расхождений.

В русском предложении Тут послышалось слово: «Докт ора!» ... [7, с. 56] субъект речи формально не выражен, тогда как в переводе на немецкий язык говорящий представлен неопределенным местоимением јеmand - кmо-то. - «Einen Arzt!», rief jemand... [6, c. 88]. Следует отметить: в немецком предложении благодаря использованию глагола rufen местоимение jemand указывает на активную роль субъекта, в то время как в русском варианте роль невыраженного индивидуума пассивна - он реципиент.

В качестве специального средства формального устранения семантического субъекта можно рассматривать актуализацию мужского, женского и среднего рода в генерализирующем значении.

Например:

1. ... что здесь дело нечисто, это понятно даже ребенку [7, с. 106].

2. Dass hier was nicht mit rechten Dingen zugeht, kapiert doch ein Kind [6, c. 163].

В этом примере грамматический род реализуется безотносительно к конкретному референту. Реальная гендерная принадлежность субъекта или субъектов, на который или которых указывает существительное остается невыявленной. Употребление неопределённого артикля немецкого языка актуализирует обобщающее значение, которое семантически соответствует множественному числу существительных:

Например:

1. Seine Beobachtungsgabe war gewiss nicht schlechter als die e ines Schriftstellers! [6, c. 499].

2. Ах, умен был Арчибальд Арчибальдович! А уж наблюдателен, пожалуй, не менее, чем и сами п и са тели $[7$, с. 330].

Морфосинтаксические средства выражения семантического субъекта регулярно пересекаются с лексическими средствами, взаимно дополняя друг друга:

Например:

1. Wieder ging oben die Tür, und diesmal kam eine ganze Gesellschaft die Treppe herunter, aber nicht im Laufschritt, sondern so, wie alle Menschen gehen [6, c. 414].

2. Дверь наверху вновь открыли, и теперь сверху начала спускаться целая ком пания, но не бегом, а обыкновенно, как все люди ходят [7, с. 274].

В приведенных примерах в качестве генерализующих средств выражения семантического субъекта выступают: собирательное существительное (Gesellschaft (f) - компания), в немецком языке - неопределённое местоимение, уточнённое нарицательным существительным (alle Menschen), в русском языке - определённое местоимение, уточнённое нарицательным существительным (все люди), а также, как в русском, так и в немецком употребление глагола настоящего времени, называющего в данном контексте безотносительное ко времени действие (gehen - ходят). Кроме того, обобщенное значение в рассмотренных выше предложениях усиливают сравнительные обороты: kapiert doch ein Kind - это nонятно даже ребенку; als die eines Schriftstellers - чем и сами nисатели; wie alle Menschen gehen - как все люди ходят.

В качестве особой лексико-грамматической группы средств выражения семантического субъекта, объединяющей свойства лексических и грамматических групп [4, с. 224, 233], нами рассматриваются фразеологизированные речевые сочетания.

Например:

1. И ни одна душа не будет знать об этом посещении [7, с. 211].

2. Außerdem wird keine Menschenseele von diesem Besuch erfahren. Dafür bürge ich Ihnen nun wirklich [6, C. 319].

Таким образом, номенклатура лексических и морфосинтаксических средств выражения одушевлённого семантического субъекта демонстрирует свойство уни- 
версальности категории обобщённости как в немецком, так и русском языке [5, с. 435].

Как показал анализ фактического материала, наибольшей степенью обобщённости обладают немецкие синтаксические конструкции с неопределённо-личным местоимением man в сочетании с модальными глаголами настоящего времени и пассивные конструкции с неназванным субъектом действия. Субъект в высказываниях с данными морфосинтаксическими средствами отличается также высокой степенью качественной неопределённости для говорящего.

Средняя степень качественной неопределённости субъекта эксплицируется множественным числом нарицательных существительных, представляющих ряд схожих субъектов, а также мужским, женским и средним родом в обобщающем значении, поскольку здесь присутствует указание на объединяющий обозначаемые субъекты признак. Дополнительное значение обобщенности в немецком языке проявляют такие морфосинтаксические средства, как: неопределённый артикль; нулевой артикль перед существительными в форме множественного числа, сравнительные обороты.

Высокую степень обобщённости в русском языке демонстрируют неопределённо-личные предложения с глаголами в третьем лице множественного числа с невыраженным деятелем и безличные предложения с модальными предикатами. За ними следуют пассивные конструкции с неназванным инициатором действия. Обозначаемый в высказываниях данными речевыми средствами субъект не определён для отправителя либо его номинация в контексте данной речевой ситуации несущественна.

Средняя степень качественной неопределённости в русском языке, как и в немецком, обозначается множественным числом нарицательных существительных, представляющих ряд схожих субъектов, а также мужским, женским и средним родом в сравнительных оборотах, генерализирующих значение субъекта.

Анализ обобщающих высказываний подтвердил неразрывную лексико-грамматическую связь и свойственную им прагматическую функцию: морфологические и синтаксические средства регулярно пересекаясь с лексическими средствами, служат формальным средством устранения семантического субъекта.

Алгоритмы формального устранения субъекта в обобщающих высказываниях схожи в различных языковых системах, в том числе в немецкой и в русской. При этом средствам выражения формального устранения субъекта в обобщающих высказываниях обоих языков присущи собственные лексико-грамматические особенности.

Проведенный сопоставительный анализ продемонстрировал тесную связь категории обобщенности с категориями определённости / неопределённости, единичности / множественности. В это проявился синкретизм, свойственный высказываниям с обобщающим значением.

\section{ЛИТЕРАТУРА}

1. Engelberg, St., Holler, A., Proost, K. Sprachliches Wissen zwischen Lexikon und Grammatik. - Berlin, Boston: de Gruyter, 2011. S. 265-313. (Institut für Deutsche Sprache. Jahrbuch 2010), https://doi.org/10.1515/9783110262339.285.

2. Blühdorn, H. Generische Referenz- ein semantisches oder ein pragmatisches Phänomen? // Deutsche Sprache Jg. 29 (2001) H. 1, S. 1-19.

3. Eichinger L.M. Gibt es einen unbestimmten Artikel im Plural - und warum nicht? // Marillier, Jean-Frangois / Dalmas, Martine / Behr, Irmtraud (Hg.) (2006): Text und Sinn. Studien zu Syntax und Deixis im Deutschen und Französischen. Festschrift für Marcel Vuillaume zum 60. Geburtstag (Eurogermanistik 23) Tübingen: Stauffenburg, S. 15-41.

4. Kuiper K. Phraseologie aus der Sicht der generativen Grammatik Erschienen // Steyer, Kathrin (Hrsg.): Wortverbindungen - mehr oder weniger fest. - Berlin [u.a.]: de Gruyter, 2004. S. 222-237. (Jahrbuch des Instituts für Deutsche Sprache 2003) DOl: https://doi.org/10.1515/9783110622768-011

5. Червоный, А.М. Семантический субъект в обобщающих высказываниях русского и французского языков // Сборник статей по итогам IV-й международной конференции «Язык и действительность. Научные чтения на кафедре романских языков им. В.Г. Гака». Том 3. - М.: Издательство «Спутник +», 2019. - 465 c. - C. 432-440.

6. Bulgakov, M. (1985) Gesammelte Werke; Teil: Bd. 3., Der Meister und Margarita : Roman [aus dem Russ. von Thomas Reschke] 3. Aufl. Berlin : Verl. Volk und Welt, 513 S.

7. Булгаков, М.А. Мастер и Маргарита : Роман / М.А. Булгаков. - М.: Современник, 1984. - 367 с. 